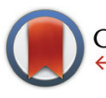

CrossMark

\& click for updates

Cite this: Dalton Trans., 2016, 45 15963

Received 9th May 2016,

Accepted 1st July 2016

DOI: $10.1039 / c 6 d t 01816$ e

www.rsc.org/dalton

\section{An electron poor iridium pincer complex for catalytic alkane dehydrogenation $\uparrow$}

\author{
Oleksandr O. Kovalenko and Ola F. Wendt* \\ A novel electron deficient 4,6-bis(trifluoromethyl)-1,3-phenylene diphosphinite ligand 4 was developed \\ and synthesized. Reaction of Ir precursors with ligand $\mathbf{4}$ gave chloro(hydride) pincer complex $\mathbf{5}$, which \\ demonstrated a higher TON in alkane dehydrogenation reactions compared to similar phosphinite based \\ pre-catalysts. The formation of cyclooctene (COE) and tert-butylethylene adducts of the $14 \mathrm{e}$ catalysts \\ was also studied and the COE adduct is implicated as the resting state of the catalyst. All compounds \\ were characterized by NMR spectroscopy and, in addition, the molecular structures of key complexes \\ were confirmed by $\mathrm{X}$-ray analysis.
}

\section{Introduction}

The selective functionalization of alkanes is a challenging topic in modern organic chemistry. ${ }^{1}$ One highly demanded reaction, particularly in industry, is the conversion of inert alkanes into more reactive olefins, which opens up broad possibilities for further transformations and modifications. In fact, olefins are the most important starting material for making industrial organic chemicals. Industrial catalytic alkane dehydrogenations proceed at high temperatures (ca. 400-600 $\left.{ }^{\circ} \mathrm{C}\right),{ }^{2}$ and effective homogeneous alkane dehydrogenation catalysts operating under relatively low temperature conditions are therefore highly desirable.

The first homogeneous alkane dehydrogenation catalytic systems were described in the 1980 s by Crabtree and Felkin. ${ }^{3}$ The temperature of the catalytic process was decreased down to $150{ }^{\circ} \mathrm{C}$, but the turnover numbers (TONs) were rather low due to catalyst decomposition. The results reported by Kaska and Jensen using a very robust and efficient iridium hydrido complex (I) opened up a new pincer era in catalytic alkane dehydrogenation research (Fig. 1). ${ }^{4}$

Many variations of the pincer framework have been explored including both aromatic and aliphatic backbones and the highest TONs were reported for aromatic backbones with oxygen and/or sulfur linkers on the arm..$^{5-9}$ Thus, bis-phosphinite complex II demonstrates a significantly higher TON in alkane transfer dehydrogenation compared to complex I

Centre for Analysis and Synthesis, Department of Chemistry, Lund University, P. O. Box 124, S-221 00 Lund, Sweden.E-mail: ola.wendt@chem.lu.se $\dagger$ Electronic supplementary information (ESI) available: NMR spectra. CCDC 1478500-1478503. For ESI and crystallographic data in CIF or other electronic format see DOI: 10.1039/c6dt01816e



I

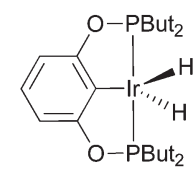

II

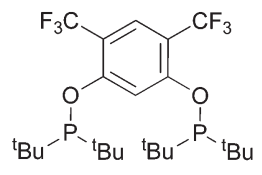

4
Fig. 1 Previously reported pincer-iridium catalysts I-II and the herein developed ligand 4 for catalytic alkane dehydrogenation.

(Fig. 1). Furthermore, the electron withdrawing substituents in the aromatic ring increase the catalyst performance. ${ }^{6}$

Based on these findings, we decided to investigate a bisphosphinite aryl backbone with two strong electron withdrawing $\mathrm{CF}_{3}$ groups in the meta-position with respect to the metallation site. This should give maximum inductive, electronic communication with the metal and, in addition, undesired orthometallated byproduct formation should be avoided. ${ }^{10}$ Thus, we herein report the synthesis of electron poor ligand 4 and its metallation to afford the corresponding iridium pincer complex. The reactivity of this complex and its catalytic activity in alkane dehydrogenation are described.

\section{Experimental section}

\section{General information}

All manipulations were carried out under a dry Ar or $\mathrm{N}_{2}$ atmosphere using standard Schlenk or glovebox techniques, unless otherwise noted. All catalytic experiments were performed under a dry $\mathrm{Ar}$ atmosphere. Hydrocarbon solvents were degassed and distilled from sodium benzophenone ketyl prior to use. Chlorinated solvents were degassed and distilled from $\mathrm{CaH}_{2}$. Silica gel with $60 \AA$ pore size and $230-400$ mesh was 
used for column chromatography. All other solvents, reagents and chemicals were used as received.

${ }^{1} \mathrm{H},{ }^{19} \mathrm{~F},{ }^{31} \mathrm{P}$, and ${ }^{13} \mathrm{C}$ NMR spectra were recorded at 400 , 376, 162 and $100 \mathrm{MHz}$, respectively, using a Bruker $400 \mathrm{MHz}$ spectrometer. For compounds 1-3 chloroform-d and for compounds 4-9 benzene- $\mathrm{d}_{6}$ were used and chemical shifts were referenced to the residual solvent peaks. ${ }^{11}$ Elemental analysis was performed by $\mathrm{H}$. Kolbe Microanalytisches Laboratorium, Mülheim an der Ruhr, Germany. High-resolution mass spectra (HRMS) were recorded on a Waters Xevo Q-TOF mass spectrometer using electrospray ionization and lock mass corrections.

\section{Crystallography}

The crystallographic measurements were performed at $293 \mathrm{~K}$ using an Oxford Diffraction Xcalibur 3 system with Mo-K $\alpha$ radiation. ${ }^{12}$ Data collection, cell refinement, and data reduction and analysis were carried out using the Xcalibur PX software, CRYSALIS CCD and CRYSALIS RED. ${ }^{13}$ Analytical absorption corrections were applied to the data using CRYSALIS RED. All structures were solved by direct methods using SHELXS-2014 and refined by a full-matrix least-squares technique based on $F^{2}$ using SHELXL-2014 with anisotropic thermal parameters for all non-H atoms. ${ }^{14}$ Hydrogen atoms were constrained to parent sites, using a riding model.

\section{Preparations}

1,3-Dibromo-4,6-bis(trifluoromethyl)benzene (1). Compound 1 was prepared according to a previously reported procedure. ${ }^{15}$ $15.07 \mathrm{~g}$ of bis(trifluoromethyl)aniline were used to give $7.75 \mathrm{~g}$ (32\%) of 1 as a pink solid.

${ }^{1} \mathrm{H}$ NMR $\left(\mathrm{CDCl}_{3}, 400 \mathrm{MHz}\right): \delta 8.12(\mathrm{~s}, 1 \mathrm{H}), 7.95(\mathrm{~s}, 1 \mathrm{H}) ;{ }^{19} \mathrm{~F}$ NMR $\left(\mathrm{CDCl}_{3}, 376 \mathrm{MHz}\right): \delta-63.07(\mathrm{~s}) ;{ }^{13} \mathrm{C} \mathrm{NMR}\left(\mathrm{CDCl}_{3}\right.$, $100 \mathrm{MHz}$ ): $\delta 140.87,129.84$ (q, $J=33.0 \mathrm{~Hz}$ ), 126.80 (sep, $J=5.5$ $\mathrm{Hz}), 124.76,122.05$ (q, $J=273.0 \mathrm{~Hz})$.

4,6-Bis(trifluoromethyl)resorcinol dibenzyl ether (2). In a $150 \mathrm{~mL}$ Schlenk flask, benzyl alcohol $(2.59 \mathrm{~mL}, 25.01 \mathrm{mmol})$ was added dropwise to a suspension of $\mathrm{KH}(25.53 \mathrm{mmol}$, $1.02 \mathrm{~g})$ in dry THF $(40 \mathrm{~mL})$ at r.t. and the reaction mixture was stirred for $4 \mathrm{~h}$ at $40^{\circ} \mathrm{C} .0 .29 \mathrm{~g}(2.01 \mathrm{mmol})$ of $\mathrm{CuBr}$ and $3.72 \mathrm{~g}$ $(10.00 \mathrm{mmol})$ of 1 were added portion-wise and the mixture was refluxed for $12 \mathrm{~h}$. The solvent was evaporated, and the residue was quenched with a saturated solution of $\mathrm{NH}_{4} \mathrm{Cl}$ in water and extracted with DCM $(4 \times 50 \mathrm{~mL})$. The combined organic layers were washed with brine and dried over $\mathrm{Na}_{2} \mathrm{SO}_{4}$ and the solvent was evaporated. The crude product was purified by column chromatography using pentane/DCM as an eluent, affording $3.75 \mathrm{~g}(88 \%)$ of the target compound 2 as a white solid.

${ }^{1} \mathrm{H}$ NMR $\left(\mathrm{CDCl}_{3}, 400 \mathrm{MHz}\right): \delta 7.81(\mathrm{~s}, 1 \mathrm{H}), 7.46-7.32(\mathrm{~m}$, $10 \mathrm{H}), 6.61(\mathrm{~s}, 1 \mathrm{H}), 5.16(\mathrm{~s}, 4 \mathrm{H}) ;{ }^{19} \mathrm{~F} \mathrm{NMR}\left(\mathrm{CDCl}_{3}, 376 \mathrm{MHz}\right)$ : $\delta-61.55(\mathrm{~s}) ;{ }^{13} \mathrm{C} \mathrm{NMR}\left(\mathrm{CDCl}_{3}, 100 \mathrm{MHz}\right): \delta 160.38,135.33$, 128.86, 128.39, 126.78, 126.54 (sep, $J=5.5 \mathrm{~Hz}$ ), 123.27 (q, $J=$ $269.7 \mathrm{~Hz}$ ), 111.14 (q, $J=32.0 \mathrm{~Hz}$ ), 99.26, 70.70. HRMS (ESI, $m / z)$ calcd for $\mathrm{C}_{22} \mathrm{H}_{15} \mathrm{O}_{2} \mathrm{~F}_{6}\left[\mathrm{M}-\mathrm{H}^{+}\right]$: 425.0976; found: 425.0976 .
4,6-Bis(trifluoromethyl)resorcinol (3). In a $1 \mathrm{~L}$ round-bottom flask, $0.38 \mathrm{~g}$ of $\mathrm{Pd} / \mathrm{C}(10 \mathrm{wt} \%)$ was added to a solution of 2 (3.75 g, $8.80 \mathrm{mmol})$ in $\mathrm{MeOH}(400 \mathrm{~mL})$. The reaction mixture was stirred overnight under a $\mathrm{H}_{2}$ atmosphere at r.t. The $\mathrm{Pd} / \mathrm{C}$ was filtered off and the solvent was evaporated. The crude product was purified by vacuum sublimation at $50{ }^{\circ} \mathrm{C}$ and $40 \mathrm{mmHg}$. Yield: $2.04 \mathrm{~g}$, 94\% of a white crystalline compound. ${ }^{1} \mathrm{H} \mathrm{NMR}\left(\mathrm{CDCl}_{3}, 400 \mathrm{MHz}\right): \delta 7.68(\mathrm{~s}, 1 \mathrm{H}), 6.55(\mathrm{~s}, 1 \mathrm{H}), 5.74(\mathrm{~s}$, $2 \mathrm{H}) ;{ }^{19} \mathrm{~F} \mathrm{NMR}\left(\mathrm{CDCl}_{3}, 376 \mathrm{MHz}\right): \delta-59.95(\mathrm{~s}) ;{ }^{13} \mathrm{C} \mathrm{NMR}$ $\left(\mathrm{CDCl}_{3}, 100 \mathrm{MHz}\right): \delta 157.68,126.59$ (sep, $J=5.0 \mathrm{~Hz}$ ), 123.51 (q, $J=270.0 \mathrm{~Hz}$ ), $109.67(\mathrm{q}, J=32.0 \mathrm{~Hz}), 106.54$. HRMS (ESI, $m / z)$ calcd for $\mathrm{C}_{8} \mathrm{H}_{3} \mathrm{O}_{2} \mathrm{~F}_{6}\left[\mathrm{M}-\mathrm{H}^{+}\right]$: 245.0033; found: 245.0037 .

((4,6-Bis(trifluoromethyl)-1,3-phenylene)bis(oxy))bis(di-tertbutylphosphine) (4). In a Schlenk flask, KH (0.060 g, $1.49 \mathrm{mmol})$ was added to a solution of $3(0.350 \mathrm{~g}, 1.42 \mathrm{mmol})$ in THF $(10 \mathrm{~mL})$ and the mixture was stirred for $4 \mathrm{~h}$ at $40{ }^{\circ} \mathrm{C}$. Di-tert-butylchlorophosphine $(0.283 \mathrm{~mL}, 1.49 \mathrm{mmol})$ was added dropwise and the mixture was stirred overnight at room temperature. Then, the procedure was repeated with new $\mathrm{KH}$ (0.060 g, $1.49 \mathrm{mmol})$ and di-tert-butylchlorophosphine (0.289 mL, $1.52 \mathrm{mmol})$. Finally, all volatiles were evaporated, $3 \mathrm{~mL}$ of dry benzene was added and the precipitate was filtered off. Removal of the solvent in vacuo yielded a yellow solid, which was dissolved in $3 \mathrm{ml}$ of pentane. The solution was cooled down to $-21{ }^{\circ} \mathrm{C}$ in order to induce crystallization. Yield: $0.395 \mathrm{~g}(52 \%)$ of white crystals. ${ }^{1} \mathrm{H}$ NMR $\left(\mathrm{C}_{6} \mathrm{D}_{6}\right.$, $400 \mathrm{MHz}): \delta 8.42(\mathrm{t}, J=8.0 \mathrm{~Hz}, 1 \mathrm{H}), 7.84(\mathrm{~s}, 1 \mathrm{H}), 1.08(\mathrm{~d}, J=$ $12.0 \mathrm{~Hz}, 36 \mathrm{H}) ;{ }^{19} \mathrm{~F}$ NMR $\left(\mathrm{C}_{6} \mathrm{D}_{6}, 376 \mathrm{MHz}\right): \delta-60.49(\mathrm{~s}) ;{ }^{31} \mathrm{P}$ NMR $\left(\mathrm{C}_{6} \mathrm{D}_{6}, 162 \mathrm{MHz}\right): \delta 156.05(\mathrm{~m}) ;{ }^{13} \mathrm{C}$ NMR $\left(\mathrm{C}_{6} \mathrm{D}_{6}\right.$, $100 \mathrm{MHz}): \delta 161.60(\mathrm{~d}, J=11.0 \mathrm{~Hz}), 126.63(\mathrm{sep}, J=5.0 \mathrm{~Hz})$, $123.81(\mathrm{q}, J=269.5 \mathrm{~Hz}), 111.85(\mathrm{q}, J=31.0 \mathrm{~Hz}), 106.90(\mathrm{t}, J=$ $27.5 \mathrm{~Hz}), 35.71(\mathrm{~d}, J=27.0 \mathrm{~Hz}), 26.81$ (d, $J=16.0 \mathrm{~Hz})$.

$\mathbf{C F}_{3}$ (POCOP)IrHCl (5). Method A. In a thick wall Straus flask, compound 4 (0.104 g, $0.195 \mathrm{mmol})$ and cyclooctadiene iridium chlorido dimer $\left[\operatorname{Ir}\left(\mu^{2}-\mathrm{Cl}\right)(\mathrm{COD})\right]_{2}(0.065 \mathrm{~g}, 0.097 \mathrm{mmol})$ were combined in toluene. The reaction vessel was sealed, placed in an oil bath and stirred overnight at $120{ }^{\circ} \mathrm{C}$. The toluene was removed under vacuum and the dark brown residue was purified by column chromatography gradually changing the eluent from hexane $(100 \%)$ to hexane:DCM (2:1). Removal of the solvent gave $0.096 \mathrm{~g}, 65 \%$ of a red solid. Deep red crystals suitable for X-ray analysis were obtained by slow evaporation of the hexane solution under an argon atmosphere.

Method B. In a thick wall Straus flask, compound 4 (0.214 g, $0.400 \mathrm{mmol})$ and chlorobis(cyclooctene)iridium dimer $\left[\operatorname{Ir}\left(\mu^{2}-\mathrm{Cl}\right)(\mathrm{COE})_{2}\right]_{2}(0.179 \mathrm{~g}, 0.200 \mathrm{mmol})$ were combined in benzene. The reaction vessel was sealed, placed in an oil bath and stirred overnight at $90{ }^{\circ} \mathrm{C}$. The solvent was removed under vacuum and the dark brown residue was purified by column chromatography gradually changing the eluent from hexane $(100 \%)$ to hexane : DCM $(2: 1)$. Removal of the solvent gave $0.261 \mathrm{~g}, 86 \%$ of a red solid. ${ }^{1} \mathrm{H}$ NMR $\left(\mathrm{C}_{6} \mathrm{D}_{6}, 400 \mathrm{MHz}\right)$ : $\delta 7.57$ (s, 1H), 1.20 (vt, $J=15.0 \mathrm{~Hz}, 18 \mathrm{H}), 1.15$ (vt, $J=15.0 \mathrm{~Hz}$, $18 \mathrm{H}),-40.44(\mathrm{t}, J=14.0 \mathrm{~Hz}, 1 \mathrm{H}) ;{ }^{19} \mathrm{~F}$ NMR $\left(\mathrm{C}_{6} \mathrm{D}_{6}, 376 \mathrm{MHz},\right)$ : $\delta-61.74(\mathrm{~s}) ;{ }^{31} \mathrm{P}$ NMR $\left(\mathrm{C}_{6} \mathrm{D}_{6}, 162 \mathrm{MHz}\right): \delta 184.73(\mathrm{~m}) ;{ }^{13} \mathrm{C} \mathrm{NMR}$ 
$\left(\mathrm{C}_{6} \mathrm{D}_{6}, 100 \mathrm{MHz}\right): \delta 165.88(\mathrm{vt}, J=12.0 \mathrm{~Hz}), 124.15(\mathrm{t}, J=3.0$ $\mathrm{Hz}), 123.63$ (q, $J=270.0 \mathrm{~Hz}$ ), 120.79 (sep, $J=5.0 \mathrm{~Hz}$ ), 108.35 (qvt, $J=32.3 \mathrm{~Hz}, J=9.6 \mathrm{~Hz}), 43.02(\mathrm{vt}, J=22.0 \mathrm{~Hz}$ ), 39.50 (vt, $J=$ $22.0 \mathrm{~Hz}$ ), 26.90 (vt, $J=6.6 \mathrm{~Hz}$ ). Anal. Calcd for $\mathrm{C}_{24} \mathrm{H}_{38} \mathrm{O}_{2} \mathrm{P}_{2} \mathrm{IrClF}_{6}$ : C, 37.82; H, 5.03. Found C, 38.22, H, 5.22.

${ }^{t} \mathbf{B u}_{2} \mathbf{P}(\mathbf{O H})$ (COD)IrCl (6). Compound 6 was obtained as a byproduct using method A for the synthesis of complex 5 and purified by column chromatography using hexane : DCM $(9: 1)$ as the eluent. Yield: $9 \mathrm{mg}, 9 \%$ of pale red solid. Single crystals suitable for X-ray analysis were obtained by recrystallization from pentane. Spectroscopic data of compound 6 were reported previously by Buono and coworkers. ${ }^{16}$

CF $_{3}$ (POCOP)Ir(L) (7). Complex 5 (0.0100 g, $\left.0.0131 \mathrm{mmol}\right)$ and ${ }^{t} \mathrm{BuONa}(0.0014 \mathrm{~g}, 0.0144 \mathrm{mmol})$ were placed in a Straus flask. Degassed dry benzene $(0.6 \mathrm{~mL})$ was distilled into the reaction vessel, and the mixture was stirred overnight at room temperature and then filtered through a PTFE filter $(0.2 \mu \mathrm{m})$. Removal of volatiles in vacuo yielded an orange solid. ${ }^{1} \mathrm{H}$ NMR $\left(\mathrm{C}_{6} \mathrm{D}_{6}, 400 \mathrm{MHz}\right): \delta 7.70(\mathrm{~s}, 1 \mathrm{H}), 1.01$ (vt, $\left.J=15.0 \mathrm{~Hz}, 36 \mathrm{H}\right) ;{ }^{19} \mathrm{~F}$ NMR $\left(\mathrm{C}_{6} \mathrm{D}_{6}, 376 \mathrm{MHz}\right): \delta-61.45(\mathrm{~s}) ;{ }^{31} \mathrm{P}$ NMR $\left(\mathrm{C}_{6} \mathrm{D}_{6}\right.$, $162 \mathrm{MHz}): \delta 188.64(\mathrm{~m}) .{ }^{13} \mathrm{C} \mathrm{NMR}\left(\mathrm{C}_{6} \mathrm{D}_{6}, 100 \mathrm{MHz}\right): \delta 166.41$ (vt, $J=13.2 \mathrm{~Hz}), 149.97$ (t, $J=5.0 \mathrm{~Hz}), 124.37$ (q, $J=271.4 \mathrm{~Hz}$ ), 122.06 (sep, $J=5.0 \mathrm{~Hz}$ ), 107.75 (qvt, $J=32.2 \mathrm{~Hz}, J=10.2 \mathrm{~Hz}$ ), 40.39 (vt, $J=23.4 \mathrm{~Hz}), 27.22(\mathrm{vt}, J=5.1 \mathrm{~Hz})$.

$\mathbf{C F}_{3}$ (POCOP)Ir(COE) (8). $0.018 \mathrm{~mL}(0.140 \mathrm{mmol})$ of degassed dry COE was added to a $0.500 \mathrm{~mL}$ benzene solution of 7 $(0.010,0.014 \mathrm{mmol})$ in a J. Young NMR tube. All volatiles were evaporated and $0.510 \mathrm{~mL}$ of degassed dry deuterated benzene was added. This resulted in a deep red solution which was analyzed by NMR spectroscopy. Deep red crystals suitable for X-ray analysis were obtained by slow evaporation of benzene under an argon atmosphere. ${ }^{1} \mathrm{H}$ NMR $\left(\mathrm{C}_{6} \mathrm{D}_{6}, 400 \mathrm{MHz}\right): \delta 7.79(\mathrm{~s}, 1 \mathrm{H})$, 4.58-4.48 (m, 2H), 2.55-2.45 (m, 2H), 2.05-1.95 (m, 2H), 1.68-1.57 (m, 4H), 1.48-1.33 (m, 4H), 1.27 (vt, $J=14.0 \mathrm{~Hz}$, $36 \mathrm{H}) ;{ }^{19} \mathrm{~F}$ NMR $\left(\mathrm{C}_{6} \mathrm{D}_{6}, 376 \mathrm{MHz}\right): \delta-61.04(\mathrm{~s}) ;{ }^{31} \mathrm{P}$ NMR $\left(\mathrm{C}_{6} \mathrm{D}_{6}\right.$, $162 \mathrm{MHz}$ ): $\delta 185.48$ (br s); ${ }^{13} \mathrm{C}$ NMR $\left(\mathrm{C}_{6} \mathrm{D}_{6}, 100 \mathrm{MHz}\right.$ ): $\delta 167.02$ (vt, $J=12.0 \mathrm{~Hz}), 146.62(\mathrm{t}, J=6.7 \mathrm{~Hz}), 124.35(\mathrm{q}, J=268.0 \mathrm{~Hz})$, 122.89 (sep, $J=5.0 \mathrm{~Hz}$ ), 106.41 (qvt, $J=32.6 \mathrm{~Hz}, J=10.4 \mathrm{~Hz}$ ), 64.71, 41.75 (vt, $J=19.2 \mathrm{~Hz}), 33.98,32.72,28.70$ (vt, $J=5.8 \mathrm{~Hz}$ ), 26.42 .

\section{General procedure for the catalytic dehydrogenation of COA} with TBE

Complex 5 (0.0030 g, $0.0040 \mathrm{mmol}, 1.0$ eq.), ${ }^{t} \mathrm{BuONa}(0.0006 \mathrm{~g}$, $0.0060 \mathrm{mmol}, 1.5$ eq.), degassed dry cyclooctane (COA) (1.631 mL, $12.12 \mathrm{mmol}, 3030$ eq.) and tert-butylethylene (TBE) (1.562 mL, $12.12 \mathrm{mmol}, 3030$ eq.) were placed in a Straus flask. The flask was sealed and fully immersed into a pre-heated oil bath with the specified temperature and time. Thereafter, the flask was cooled down in an ice bath and the sample was analyzed by NMR spectroscopy. Three runs were performed to determine the average TONs. No compounds other than COA, cyclooctene (COE), cyclooctadiene (COD), TBE and tert-butylethane (TBA) could be detected by ${ }^{1} \mathrm{H}$ NMR spectroscopy. This procedure was used also for other iridium complexes.

\section{Results and discussion}

\section{Synthesis and characterization of ligands and complexes}

Ligand 4 was synthesized in five steps following the strategy described in Scheme 1, starting from bis(trifluoromethyl) aniline. Compound $\mathbf{1}$ was obtained in 32\% yield following a previously described procedure of Williams et al. ${ }^{15}$ All attempts to obtain key resorcinol 3 in one step from 1 using either tetrabutylammonium hydroxide or alkali metal hydroxide media following reported catalytic protocols were unsuccessful, probably due to the electron poor nature of structure $\mathbf{1}$ and the necessity to substitute two bromine atoms at the same time. ${ }^{17}$ Instead, the synthesis of benzyl ester 2 was performed using an Ullmann-type reaction with $\mathrm{CuBr}$ as the catalyst. ${ }^{18}$ Thus, the target ligand 4 was obtained in 14\% total yield and fully characterized by ${ }^{31} \mathrm{P},{ }^{19} \mathrm{~F},{ }^{13} \mathrm{C}$ and ${ }^{1} \mathrm{H}$ NMR spectroscopy. Its structure was confirmed with a single crystal X-ray analysis and the molecular structure is given in Fig. 2. This shows that the trifluoromethyl groups cause substantial steric hindrance, obstructing the free rotation of the phosphinite groups across the $\mathrm{C}-\mathrm{O}$ bond. Hence, the arms of the pincer ligand are oriented in the same direction, possibly providing some assistance in the cyclometallation reactions.

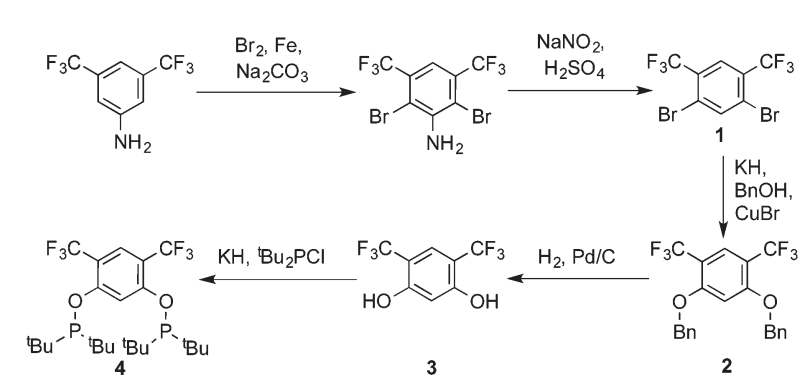

Scheme 1 Synthesis of ligand 4.

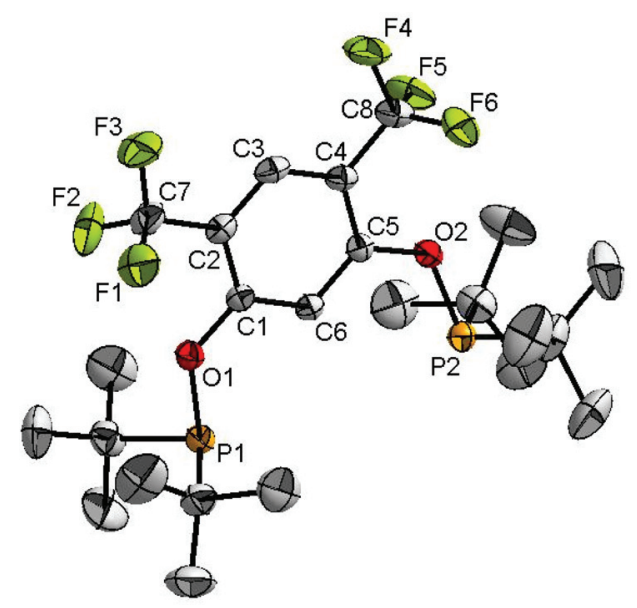

Fig. 2 The molecular structure of compound 4. Thermal ellipsoids are drawn at the $30 \%$ probability level. Hydrogen atoms are omitted for clarity. Selected bond lengths (Å) and angles ( ${ }^{\circ}$ ): C1-O1 1.359(3), O1-P1 1.6915(18), C5-O2 1.360(3), O2-P2 1.6937(18), C1-O1-P1 122.83(15), C5-O2-P2 122.80(15). 
The reaction progress of the cyclometallation of ligand 4 with iridium precursors could be conveniently monitored by ${ }^{31} \mathrm{P}\left\{{ }^{1} \mathrm{H}\right\}$ and/or ${ }^{19} \mathrm{~F}\left\{{ }^{1} \mathrm{H}\right\}$ NMR spectroscopy. After stirring 4 with the cyclooctadiene iridium chloride dimer $\left[\operatorname{Ir}\left(\mu^{2}-\mathrm{Cl}\right)(\mathrm{COD})\right]_{2}$ in toluene at room temperature for one hour, an orange precipitate was formed and no signal could be observed in the ${ }^{31} \mathrm{P}\left\{{ }^{1} \mathrm{H}\right\}$ NMR spectrum. This behaviour is typical in the formation of non-cyclometallated dimers, which usually have very low solubility. ${ }^{19}$ However, in this case the dimer could be transformed further; heating the reaction mixture at $120{ }^{\circ} \mathrm{C}$ dissolved the precipitate, forming a deep red solution. There was

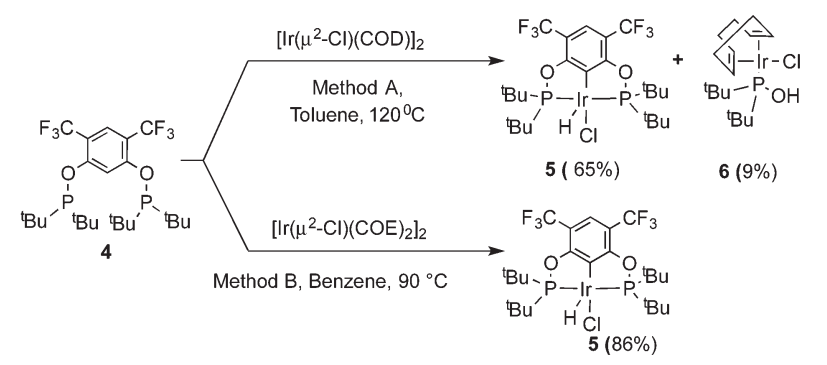

Scheme 2 Synthesis of complex 5.

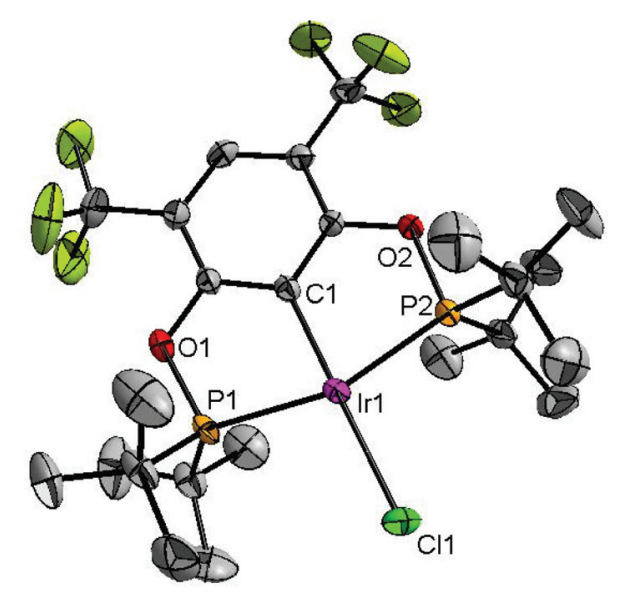

Fig. 3 The molecular structure of complex 5. Thermal ellipsoids are drawn at the $30 \%$ probability level. Hydrogen atoms are omitted for clarity. Selected bond lengths (Å) and angles ( $\left.{ }^{\circ}\right)$ : Ir1-C1 1.997(5), Ir1-P1 2.2946(15), Ir1-P2 2.2919(15), Ir1-Cl1 2.3840(16), P1-Ir1-P2 160.59(5), C1-Ir1-Cl1 174.67(15). a concomitant appearance of new signals at $184.73 \mathrm{ppm}$ and -61.74 ppm in the ${ }^{31} \mathrm{P}\left\{{ }^{1} \mathrm{H}\right\}$ and ${ }^{19} \mathrm{~F}\left\{{ }^{1} \mathrm{H}\right\}$ NMR spectra, correspondingly. From this reaction the iridium hydrido chloride complex, 5, was obtained in $65 \%$ yield ( $c f$. Scheme 2 ). The ${ }^{1} \mathrm{H}$ NMR spectrum of $\mathbf{5}$ displays the characteristic hydride triplet at $-40.44 \mathrm{ppm},{ }^{6 b}$ and the molecular structure was also confirmed using X-ray crystallography (Fig. 3). As seen from the figure, the iridium atom displays a distorted square-pyramidal geometry assuming that the hydride is in an axial position. The complex has the usual P-Ir-P angle of less than $180^{\circ}$ and the Ir-P bond lengths are very similar. The electron withdrawing nature of the ligand is displayed in the unusually short $\mathrm{Ir}-\mathrm{Cl}$ distance of 2.384(2) $\AA$, which is ca. $0.01 \AA$ shorter than the corresponding unsubstituted one (Table 1). ${ }^{19 b}$

In addition to the main product $\mathbf{5}$, complex $\mathbf{6}$ was isolated as a byproduct in $9 \%$ yield (Scheme 2 ). We could establish the molecular structure of 6 using single crystal X-ray analysis; the molecular structure is given in Fig. 4. This compound was previously synthesized and characterized by Buono and coworkers, ${ }^{16}$ but in our hands it crystallizes in a higher symmetry space group, $P 2_{1} / n$. From the structure it is evident that iridium cleaved the $\mathrm{C}-\mathrm{O}$ bond in one of the pincer phosphinite arms, forming a di(tert-butyl)phosphinous acid iridium complex with a distorted square planar geometry. Such a C-O bond cleavage in pincer complexes has been observed previously. ${ }^{20}$

\section{Dehydrogenation catalysis}

In order to investigate the catalytic activity in alkane transfer dehydrogenation reactions, we chose a common benchmark reaction - transfer dehydrogenation of cyclooctane in the presence of tert-butylethylene (TBE). The standard conditions and COA/TBE/catalyst ratio (3030/3030/1) were used in the initial catalytic studies, which gave us the possibility to compare catalyst 5 with previously reported ones. ${ }^{6,7}$ To generate an active catalyst, ${ }^{t} \mathrm{BuONa}$ (1.5 eq.) was added in order to remove $\mathrm{HCl}$ from 5. This formed a compound, 7 , which could be isolated as an orange solid and characterized by ${ }^{31} \mathrm{P},{ }^{19} \mathrm{~F},{ }^{13} \mathrm{C}$ and ${ }^{1} \mathrm{H}$ NMR spectroscopy. The ${ }^{31} \mathrm{P}$ and ${ }^{19} \mathrm{~F}\left\{{ }^{1} \mathrm{H}\right\}$ NMR spectra contain signals at $188.64 \mathrm{ppm}$ and a sharp singlet at $-61.45 \mathrm{ppm}$, respectively. Furthermore, the ${ }^{1} \mathrm{H}$ NMR spectrum only contains signals from the ligand with no indication of any dynamic behaviour as previously observed for more electron rich pincer systems. ${ }^{22}$ It seems unlikely that 7 is a $14 \mathrm{e}$ complex and we tentatively

Table 1 Select bond lengths ( $(\AA)$ for electron-rich and -deficient pincer phosphinite complexes. ${ }^{6 b, 19 b, 21,25 b}$

\begin{tabular}{|c|c|c|c|c|c|c|}
\hline & ${ }^{\mathrm{Bu}}{ }_{2} \mathrm{P} \underset{\mathrm{H}^{\prime} \mathrm{Cl}}{\mathrm{I}}$ & & ${ }_{\mathrm{H}}^{\mathrm{t}} \mathrm{Bu}_{2} \mathrm{Cl}$ &  & ${ }_{\mathrm{Bu}_{2}}^{\mathrm{P}} \underset{\mathrm{H}^{\prime}}{\mathrm{Cl}}-\underset{\text { ref. }^{[6 \mathrm{~b}]}}{\mathrm{P}^{\mathrm{t}} \mathrm{Bu}_{2}}$ & ${ }_{\mathrm{Bu}_{2}}^{\mathrm{P}}$ \\
\hline $\mathrm{Ir}-\mathrm{Cl}$ & $2.3840(16)$ & $2.3933(13)$ & $2.3947(12)$ & $2.3954(8)$ & $2.4044(14)$ & $2.4115(12)$ \\
\hline Ir-C(1) & $1.997(5)$ & $1.992(4)$ & $2.000(3)$ & $1.996(3)$ & $2.004(5)$ & $2.014(4)$ \\
\hline $\mathrm{Ir}-\mathrm{P}(1)$ & $2.2946(15)$ & $2.2871(13)$ & $2.2897(10)$ & $2.2890(8)$ & $2.2949(16)$ & $2.2944(12)$ \\
\hline $\mathrm{Ir}-\mathrm{P}(2)$ & $2.2919(15)$ & $2.2864(13)$ & $2.2925(11)$ & $2.2940(8)$ & $2.2889(15)$ & $2.2926(11)$ \\
\hline
\end{tabular}




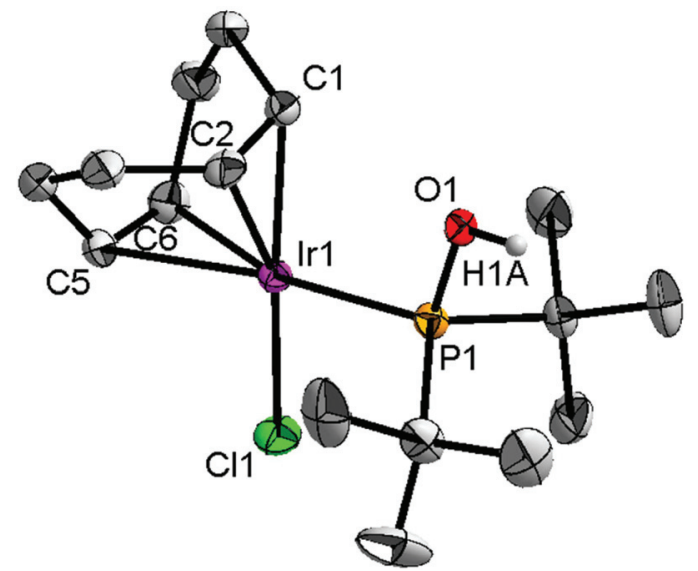

Fig. 4 The molecular structure of complex 6. Thermal ellipsoids are drawn at the $30 \%$ probability level. Hydrogen atoms are omitted for clarity. Selected bond lengths $(\AA)$ and angles $\left(^{\circ}\right)$ : Ir1-C1 2.125(5), Ir1-C2 2.117(5), Ir1-C5 2.228(5), Ir1-C6 2.217(5), Ir1-Cl1 2.3573(13), Ir1-P1 2.2728(13), P1-O1 1.593(3), P1-Ir1-Cl1 94.74(5), Ir1-P1-O1 110.76(13).

describe it as the benzene adduct. The electron poor ligand in 7 probably prohibits dynamic oxidative addition/reductive elimination of benzene (see the ESI†). However, it is likely that there is a fast benzene exchange at the metal centre (without oxidative addition). Attempts to characterize 7 with elemental analysis failed since it quickly forms a dinitrogen complex.

After heating the reaction vessel for $24 \mathrm{~h}$ at $200{ }^{\circ} \mathrm{C}$, complex 7 demonstrated a turnover number (TON) of 2086. This value is higher than the original Brookhart's catalyst with an unsubstituted benzene ring and also slightly higher than values obtained using other electron withdrawing substituents (Table 3) ${ }^{6,8}$ A temperature screening was performed and an improved performance of 7 was detected at $170{ }^{\circ} \mathrm{C}$ (Table 2); thus, this temperature was used for the following experiments. A kinetic study showed that around $80 \%$ of the turnovers were observed within the first 8 hours of the reaction and $\approx 90 \%$ after $24 \mathrm{~h}$. Prolonged heating did not improve turnovers substantially (Table 4 and Fig. 5). An initial TOF could be calculated and it was around $0.8 \mathrm{~s}^{-1}$, which is lower than that reported for $\left\{p-\mathrm{C}_{6} \mathrm{~F}_{5}-\mathrm{C}_{6} \mathrm{H}_{2}\left(\mathrm{OCH}_{2} \mathrm{P}^{t} \mathrm{Bu}_{2}\right)_{2}\right\} \mathrm{Ir}$, but on the other hand our experiment was performed at a $30{ }^{\circ} \mathrm{C}$ lower temperature. For a direct comparison the same experiment was

Table 2 Temperature screening in transfer dehydrogenation of COA with TBE catalyzed by in situ-generated complex 7

\begin{tabular}{ll}
\hline$t\left[{ }^{\circ} \mathrm{C}\right]^{a}$ & TONs $^{b}$ \\
\hline 150 & 1551 \\
160 & 2276 \\
170 & 2324 \\
180 & 2109 \\
200 & 2086
\end{tabular}

${ }^{a}$ Average of three runs, using a $3030: 3030: 1$ ratio of COA/TBE/ precatalyst 5 and 1.5 equiv. of ${ }^{t} \mathrm{BuONa}$ for $24 \mathrm{~h} .{ }^{b}$ Determined by ${ }^{1} \mathrm{H}$ NMR, the sum of COE and COD double bonds equals the TON of TBE within $2 \%$ difference.
Table 3 Various iridium phosphinite catalysts in the catalytic dehydrogenation of $\mathrm{COA}^{6,8}$





${ }^{a}$ Results were obtained using a 3030:3030:1 ratio of COA/TBE/ precatalyst and ${ }^{t} \mathrm{BuON}$ under an argon atmosphere. TONs were determined by ${ }^{1} \mathrm{H}$ NMR. ${ }^{b}$ Obtained at $170{ }^{\circ} \mathrm{C}$ for $40 \mathrm{~h}$. ${ }^{c}$ Obtained at $200{ }^{\circ} \mathrm{C}$ for $24 \mathrm{~h} .{ }^{d}$ Obtained at $200{ }^{\circ} \mathrm{C}$ for $40 \mathrm{~h}$.

Table 4 Catalytic activity of in situ-generated complex 7 in the transfer dehydrogenation of COA with TBE

\begin{tabular}{|c|c|c|c|c|c|}
\hline $\mathrm{CC}$ & & TBE & & COE & COD \\
\hline Entry $^{a}$ & $t[\mathrm{~h}]$ & TONs $^{b}$ & Entry $^{a}$ & $t[\mathrm{~h}]$ & TONs $^{b}$ \\
\hline 1 & 0.17 & 625 & 7 & 8 & 1985 \\
\hline 2 & 0.5 & 1117 & 8 & 15 & 2174 \\
\hline 3 & 1 & 1382 & 9 & 24 & 2324 \\
\hline 4 & 3 & 1781 & 10 & 40 & 2398 \\
\hline 5 & 4 & 1851 & 11 & 170 & 2537 \\
\hline 6 & 6 & 1935 & $12^{c}$ & 24 & 10 \\
\hline
\end{tabular}

${ }^{a}$ Average of three runs, using a $3030: 3030: 1$ ratio of COA/TBE/precatalyst 5 and 1.5 equiv. of ${ }^{t} \mathrm{BuONa}$, unless otherwise noted. All reactions were performed under an argon atmosphere. ${ }^{b}$ Determined by ${ }^{1} \mathrm{H}$ NMR, the sum of COE and COD double bonds equals the TON of TBE within $2 \%$ difference. ${ }^{c}$ Using a 3030:1 ratio of COA/precatalyst 5 and 1.5 equiv. of ${ }^{t} \mathrm{BuONa}$ under argon under refluxing conditions.

performed with the Brookhart catalyst (II), reproducing the literature results fairly well (Table S2 $\uparrow$ and Fig. 5). It again shows that the initial TOF of $\mathbf{5}$ is lower (at a lower temperature) but the TON is higher.

Also, catalysis without a hydrogen acceptor (TBE) was investigated. This was conducted in an open vessel protected with an argon backstop. This approach provides unimpeded hydrogen elimination from the reaction flask, but puts limits on the maximum reaction temperature because of the boiling point of $\mathrm{COA}$ and $\operatorname{COE}\left(\max . t \approx 150{ }^{\circ} \mathrm{C}\right.$ ). Under these conditions we only observed $c a$. 10 turnovers after $24 \mathrm{~h}$ (Table 4 ). 




Fig. 5 Turnover number as a function of time for 5 (at $170{ }^{\circ} \mathrm{C}$ ) and II (at $200^{\circ} \mathrm{C}$ ). The final TON of II is 1730 . See Tables 4 and S2 $\uparrow$ for details.

\section{Isolation of intermediates}

To probe the resting state of the catalyst the reaction mixture after catalysis was analyzed by ${ }^{31} \mathrm{P}\left\{{ }^{1} \mathrm{H}\right\}$ NMR spectroscopy. The presence of a dominant broad signal at 185.48 ppm was observed, which triggered us to examine the nature of the contributing species. Previous mechanistic studies ${ }^{23}$ have shown that the resting state varies with the electronic nature of the catalyst, with the lower oxidation states being favoured for more electron poor systems. ${ }^{24}$

Compound 7 reacts with COE and TBE in benzene solution at room temperature forming deep red solutions of complexes 8 and 9, correspondingly (Scheme 3). ${ }^{31} \mathrm{P}$ and ${ }^{19} \mathrm{~F}\left\{{ }^{1} \mathrm{H}\right\}$ NMR spectra demonstrate chemical shifts at $185.48 \mathrm{ppm}$, 185.45 ppm, -61.04 ppm and $-61.47 \mathrm{ppm}$, respectively. The signal from 8 agrees very well with the signal of the reaction mixture after catalysis. Evaporation of volatile TBE and benzene from the solution of $\mathbf{9}$ led to the formation of compound 7 again, and 9 could not be isolated in a pure form. Contrary to $\mathbf{9}$, complex $\mathbf{8}$ did not lose coordinated COE readily, and based on ${ }^{31} \mathrm{P},{ }^{19} \mathrm{~F},{ }^{13} \mathrm{C}$ and ${ }^{1} \mathrm{H}$ NMR studies of the deuterated benzene solutions an equilibrium was established between complex 8, precursor 7 and free $\mathrm{COE}$ in a ratio of $2: 1: 1$. Compound 8 is poorly soluble in benzene, and X-ray quality crystals were obtained and an X-ray analysis was performed to confirm the molecular structure of $\mathbf{8}$, which is given

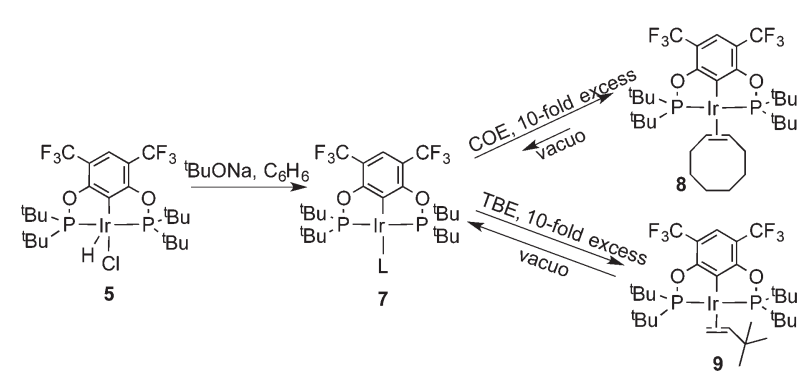

Scheme 3 Reactions of complex 5 with TBE and COE.



Fig. 6 The molecular structure of complex 8. Thermal ellipsoids are drawn at the $30 \%$ probability level. Hydrogen atoms are omitted for clarity. Selected bond lengths $(\AA)$ and angles $\left(^{\circ}\right)$ : Ir1-C1 2.032(9), Ir1-P1 2.285(5), Ir1-P2 2.315(5), Ir1-C25 2.289(12), Ir1-C26 2.230(12), C25C26 1.380(18), P1-Ir1-P2 157.15(10), C1-Ir1-C25 159.4(5), C1-Ir1-C26 160.2(7).

in Fig. 6. The structure exhibits a distorted square planar geometry with the olefin bonded perpendicular to the coordination plane. Bond lengths and angles are in good agreement with similar, previously reported complexes with coordinated ethylene and COE. The $\mathrm{C}=\mathrm{C}$ bond is 1.380(18) indicating a fairly weak back-donation from the $\operatorname{Ir}(\mathrm{I})$ metal centre. ${ }^{25,26}$

These experiments show that COE binds much more strongly than TBE to compound 7. As the COE concentration rises, the activity consequently decreases and already at moderate COE concentrations, $\mathbf{8}$ is probably the resting state of the catalyst. In keeping with the electron poorness of the ligand system there is no oxidative addition observed. As mentioned previously, 7 does not seem to undergo oxidative addition of benzene and the olefin substrates show no tendency for any vinylic $\mathrm{C}-\mathrm{H}$ oxidative addition; the oxidative addition of COA is therefore probably the rate determining step in the catalytic dehydrogenation.

\section{Conclusions}

A new electron deficient ligand $\mathbf{4}$ was synthesized and the iridium precatalyst $\mathbf{5}$ was successfully obtained and characterized. With a base, this gives the active species 7 , which could be isolated probably as the benzene adduct. The catalyst demonstrated an increase in the TON compared to other iridium phosphinite systems. Also, a relatively stable COE complex 8 was obtained and characterized. This compound is probably the resting state of the catalyst already at low conversion.

\section{Acknowledgements}

Financial support from the Swedish Research Council, the Knut and Alice Wallenberg Foundation and the Royal Physiographic Society in Lund is gratefully acknowledged. 


\section{References}

1 (a) J. F. Hartwig, J. Am. Chem. Soc., 2016, 138, 2-24; (b) J. A. Labinger and J. E. Bercaw, Nature, 2002, 417, 507514; (c) K. M. Waltz and J. F. Hartwig, Science, 1997, 277, 211-213.

2 K. Weissermel and H.-J. Arpel, Industrial Organic Chemistry, Wiley-VCH, Weinheim, 2003, pp. 59-89.

3 (a) M. J. Burk and R. H. Crabtree, J. Am. Chem. Soc., 1987, 109, 8025-8032; (b) H. Felkin, T. Fillebeen-Khan, R. Holmes-Smith and Y. Lin, Tetrahedron Lett., 1985, 26, 1999-2000.

4 (a) M. Gupta, C. Hagen, R. J. Flesher, W. C. Kaska and C. M. Jensen, Chem. Commun., 1996, 2083-2084; (b) M. Gupta, C. Hagen, W. C. Kaska, R. E. Cramer and C. M. Jensen, J. Am. Chem. Soc., 1997, 119, 840-841; (c) C. M. Jensen, Chem. Commun., 1999, 2443. For reviews, see: (d) D. Morales-Morales and C. M. Jensen, The Chemistry of Pincer Compounds, Elsevier, Amsterdam, 2007; (e) Activation and functionalization of $\mathrm{C}-\mathrm{H}$ bonds, ed. K. I. Goldberg and A. S. Goldman, ACS symposium series, American Chemical Society, Washington, DC, 2004, vol. 885; $(f)$ D. Morales-Morales, Iridium-mediated alkane dehydrogenation, in Iridium complexes in organic synthesis, ed. L. A. Oro and C. Claver, Wiley-VCH, Weinheim, 1st edn, 2009; (g) D. Bézier and M. Brookhart, Transfer Dehydrogenations of Alkanes and Related Reactions Using Iridium Pincer Complexes, in $\mathrm{C}-\mathrm{H}$ Bond Activation and Catalytic Functionalization II, ed. P. H. Dixneuf and H. Doucet, Topics in organometallic chemistry, Springer, Heidelberg, 2016, vol. 56, p. 189.

5 (a) K. Krogh-Jespersen, M. Czerw, K. Zhu, B. Singh, M. Kanzelberger, N. Darji, P. D. Achord, K. B. Renkema and A. S. Goldman, J. Am. Chem. Soc., 2002, 124, 10797-10809; (b) K. Zhu, P. D. Achord, X. Zhang, K. Krogh-Jespersen and A. S. Goldman, J. Am. Chem. Soc., 2004, 126, 13044-13053; (c) S. Kundu, Y. Choliy, G. Zhuo, R. Ahuja, T. J. Emge, R. Warmuth, M. Brookhart, K. Krogh-Jespersen and A. S. Goldman, Organometallics, 2009, 28, 5432-5444; (d) Z. Huang, M. Brookhart, A. S. Goldman, S. Kundu, A. Ray, S. L. Scott and B. C. Vicente, Adv. Synth. Catal., 2009, 351, 188-206.

6 (a) I. Göttker-Schnetmann, P. S. White and M. Brookhart, Organometallics, 2004, 23, 1766-1776; (b) I. GöttkerSchnetmann, P. White and M. Brookhart, J. Am. Chem. Soc., 2004, 126, 1804-1811.

7 W. Yao, Y. Zhang, X. Jia and Z. Huang, Angew. Chem., Int. Ed., 2014, 53, 1390-1394.

8 A. V. Polukeev, R. Gritcenko, K. J. Jonasson and O. F. Wendt, Polyhedron, 2014, 84, 63-66.

9 J. J. Adams, N. Arulsamy and D. M. Roddick, Organometallics, 2012, 31, 1439-1447.
10 (a) X. Zhang, T. J. Emge and A. S. Goldman, Inorg. Chim. Acta, 2004, 357, 3014-3018; (b) R. B. Bedford, M. E. Blake, S. J. Coles, M. B. Hursthouse and P. N. Scully, Dalton Trans., 2003, 2805-2807.

11 G. R. Fulmer, A. J. M. Miller, N. H. Sherden, H. E. Gottlieb, A. Nudelman, B. M. Stoltz, J. E. Bercaw and K. I. Goldberg, Organometallics, 2010, 29, 2176-2179.

12 Crysalis CCD, Oxford Diffraction Ltd, Abingdon, Oxfordshire, UK, 2005.

13 Crysalis RED, Oxford Diffraction Ltd, Abingdon, Oxfordshire, UK, 2005.

14 G. M. Sheldrick, Acta Crystallogr., Sect. A: Found. Crystallogr., 2008, 64, 112-122.

15 P. Brulatti, R. J. Gildea, J. A. K. Howard, V. Fattori, M. Cocchi and J. A. G. Williams, Inorg. Chem., 2012, 51, 3813-3826.

16 D. Martin, D. Moraleda, T. Achard, L. Giordano and G. Buono, Chem. - Eur. J., 2011, 17, 12729-12740.

17 (a) Y. Xiao, Y. Xu, H.-S. Cheon and J. Chae, J. Org. Chem., 2013, 78, 5804-5809; (b) J. Chen, T. Yuan, W. Hao and M. Cai, Catal. Commun., 2011, 12, 1463-1465; (c) R. Paul, M. A. Ali and T. Punniyamurthy, Synthesis, 2010, 42684272 .

18 K. Kunz, U. Scholz and D. Ganzer, Synlett, 2003, 24282439.

19 (a) D. Olsson, A. Arunachalampillai and O. F. Wendt, Dalton Trans., 2007, 5427-5433; (b) A. Arunachalampillai, D. Olsson and O. F. Wendt, Dalton Trans., 2009, 8626-8630; (c) M. T. Johnson and O. F. Wendt, Inorg. Chim. Acta, 2011, 367, 222-224.

20 K. J. Jonasson, N. Ahlsten and O. F. Wendt, Inorg. Chim. Acta, 2011, 379, 76-80.

21 N. T. Mucha and R. Waterman, Organometallics, 2015, 34, 3865-3872.

22 (a) M. Kanzelberger, B. Singh, M. Czerw, K. KroghJespersen and A. S. Goldman, J. Am. Chem. Soc., 2000, 122, 11017-11018; (b) A. V. Polukeev, R. Marcos, M. S. G. Ahlquist and O. F. Wendt, Chem. Sci., 2015, 6, 2060-2067.

23 I. Göttker-Schnetmann and M. Brookhart, J. Am. Chem. Soc., 2004, 126, 9330-9338.

24 J. Choi, A. H. R. MacArthur, M. Brookhart and A. S. Goldman, Chem. Rev., 2011, 111, 1761-1779.

25 (a) A. Kumar, T. Zhou, T. J. Emge, O. Mironov, R. J. Saxton, K. Krogh-Jespersen and A. S. Goldman, J. Am. Chem. Soc., 2015, 137, 9894-9911; (b) A. Brück, D. Gallego, W. Wang, E. Irran, M. Driess and J. F. Hartwig, Angew. Chem., Int. Ed., 2012, 51, 11478-11482; (c) Z. Huang, P. S. White and M. Brookhart, Nature, 2010, 465, 598601.

26 A. V. Polukeev and O. F. Wendt, Organometallics, 2015, 34, 4262-4271. 